\title{
公共建筑内部空间的创新设计与生态理念的结合 研究
}

刘玉诚 ${ }^{1}$ 李晓宇 ${ }^{2}$

1 河北九易庄宸科技股份有限公司 2 中国移动通信集团设计院有限公司河北分公司

DOI:10.32629/ems.v2i1.580

[摘要] 近年来, 随着我国经济水平的不断快速发展, 我国建筑行业也在不断的更新与发展, 而且在建筑行业设计中, 其内部空间的创新设计与生态理念的结合设计更是引起了人们的高度重视。人们对设计的需求就需要设计师在设计 的过程中采取科学合理的设计方案, 从而提高建筑的整体设计水平。本文主要是对公共建筑内部空间的创新设计以 及生态理念的结合研究作出了相应的分析, 希望能够给予相同行业的工作人员提供出一定价值的参考。

[关键词] 公共建筑内部空间;创新设计;生态理念;研究

\section{引言}

公共建筑在现代建筑中起着至关重要的作用, 所以 公共建筑的创新设计是保证建筑行业健康和高速发展 的重要部分。在公共建筑室内设计中,加强建筑装饰设计 的绿化环境, 提高建筑使用功能, 是室内设计需要重视的 地方。生态环保作为室内生态设计的重要设计指标, 并在 室内生态设计领域得到了充分的运用。随着人们对环境 污染和保护环境的越来越重视, 室内设计与生态理念的 结合逐渐应用到建筑装饰设计中, 并成为室内设计的主 流方向。

\section{1 公共建筑室内设计与生态设计原则}

1.1 公共建筑室内设计可持续发展原则

公共建筑室内设计,首先要以建筑、自然环境、室内 装饰等有机的融合为起点, 再与现实的建筑形态相结合, 创建生态、舒适的建筑环境设计。公共建筑室内装饰要 充分运用大自然中的各种环保资源, 要尽可能地使用可 再生的、可持续使用的环保建筑材料进行室内装修设计, 更要结合建筑物所在的地区文化以及特色建筑。这就需 要设计师从各方面设计出与自然环境相融合的、质朴 的、安全的、和谐的、闲适的室内空间设计。总之, 公共建 筑在设计过程中要充分考虑建筑内部空间的运用, 充分 考虑建筑物的形态属性,所用建筑材料的成分,生态环境 的影响以及使用者的社会属性。

\section{2 公共建筑室内设计艺术性原则}

室内设计的具体方案要重视设计的艺术感染力, 要 用美学的角度来考虑问题。在室内设计艺术性方面, 不仅 要考虑室内设计的整体颜色、形态以及装饰材料的成分, 还要充分运用植物的合理布局来对室内设计的艺术感 染力进行设计。

1.3 公共建筑室内设计要遵从以人为本的原则

建造公共建筑的目的就是为了更好的服务于人类
的生活于工作,所以在设计时要把人的体验度放在首位。 而大自然中的柳绿桃红、清新的空气和充盈的阳光都对 现代人有着极大的吸引力, 他们喜欢将自己置身于大自 然中,感受大自然宽广的胸怀。因此,室内设计不仅要能 满足人们在功能上的需求, 还要考虑是否能够满足人们 的精神需要。所以、公共建筑室内设计要遵循以人为本 的原则。

\section{4 公共建筑室内设计要遵循传统文化的原则}

每个地区的风俗文化特点都不一样, 作为当地的公 共建筑就是服务于当地人的, 所以在进行设计时一定要 更加凸显当地的传统文化特色。因此, 公共建筑室内设计 时要将景观设计与当地的风俗文化进行充分的融合。力 求在满足人们的生产生活的需求的基础上, 追求公共建 筑室内自然景观设计使之能满足人们的精神需求。

\section{2 公共建筑生态室内设计理论的分析}

2.1 地源热洜对具有生态理念的公共建筑的影响

生态建筑设计工作应重视地源热洜的作用, 并将其 应用到建筑物中。由于地源热原建设具有资金投人巨 大、管理复杂及技术要求较高等特点,因此应在设计环节 充分重视由此带来的各种问题。在地源热洜建设过程中, 按照施工方式不同, 可分为地下水源热洜及地表水源热 泵。

\section{2 公共建筑室内装饰环节}

自然肌理的材质, 可以让人们更能够感受到大自然 的气息,所以可以将其充分运用到公共建筑室内装饰中。 譬如在装饰中露出水泥、木材、石材等表现其本来面目 的设计, 这样的设计更能牵动人们心里想回归自然的情 愫。又如室内纺织品壁挂设计,使用毛、棉、麻等材料,通 过设计不同的编织风格和印染技术, 辅以精美图案所展 示的独特风格近年来备受室内生态设计专家和业内人 士的喜爱。为了达到使用者的使用舒适度, 结合环境心理 
学并充分使用自然材料, 把自然界中具有生态美感的因 素在室内环境设计中表现出来。

\section{3 公共建筑生态室内自然景观设计的策略}

3.1 必须确保公共建筑室内的健康安全

公共建筑是人们聚集活动和进行社交的地方, 因此, 其在进行室内设计时必须把健康、安全放在首位。首先, 公共建筑的室内设计要重视空气的流通, 保证室内的空 气质量。其次, 在进行室内设计的选材上一定要选择安 全、环保、对人体无害的材质。最后, 在保证健康无害的基 础上,还要选用可重复利用的材质,尽可能的节约资源。

3.2 室内设计的主题符合功能诉求

室内设计的主题, 主要要看建筑面积的大小和对空 间的运用。现代公共建筑中为了让建筑更加的富有生气, 大多运用一些自然植物、假山、水景等。在室内设计中, 采 光和朝向是非常重要的, 所以设计师要充分利用每一个 让人眼前一亮的位置。但是建筑不只是用来看的, 也需要 满足人们对功能方面的需求, 不然再美观的建筑也不能 让人们驻足。因此, 设计师要在满足功能诉求的基础上, 再进行景观设计。公众对建筑物的第一印象如何体现在 设计的每一个细节处, 因为现代的公共建筑大多是人们 用来活动和消遣的场所, 所以要根据建筑的用途来设计 主题和需要使用的元素。综上, 公共建筑的设计要注重每 一个细节,要符合当地的风俗习惯,完美的体现设计主题, 只有这样才能够真正的实现公共建筑室内景观设计的 用途。

\section{4 室内环境艺术设计中的生态理念的应用}

4.1 环保材料的运用

环保材料是指无毒、无害、无污染、健康的材料, 它的 特点是低碳、节能、环保。在室内设计中为了达到节能环 保的效果, 那就需要使用原生态的建筑装饰材料, 让室内 环境更倾向于大自然。同时, 为了让使用者能够处于轻 松、愉悦的氛围, 所选用的材料无论是材质还是色彩都能 让使用者深切的感受到大自然的魅力。

\section{2 室内空间设计}

室内设计的视觉效果主要表现在室内空间设计中, 所以在室内艺术设计中, 室内空间设计是其中最关键的 一个环节。在空间设计的时候, 为了保证室内环境的舒适 应该着重体现室内环境的整齐与亮度。这就需要设计者 以宏观的角度出发, 从生态环保理念布局, 进行室内空间 的合理设计。每个空间之间的联系和通风在对室内空间 进行划分的时要特别注意, 可以运用先进的技术将室内 外环境相互联通, 与室外的环境相互联系起来, 才能达到 互通和通风的效果。

\section{3 室内陈设设计}

在室内环境艺术设计中室内陈设起到了重要作用, 因此, 要充分重视室内陈设在室内环境设计中的地位, 并
加以重视。在室内设计中, 设计者可以运用不同的陈设品 并能驾轻就熟的将室内陈设进行各种的划分。一般来说, 室内陈设在一般会对使用者的生活、学习、工作、和习惯 产生一定程度的影响。随着生态理念的逐渐应用,绿色植 物在装饰方面的作用在室内陈设设计环节中运用逐渐 频繁, 绿色植物的作用体现为不仅能够起到良好的装饰 作用,产生良好的视觉效果还可以更好的改善空气质量。 绿色植物由于其独特的生长环境及生存空间, 可能在室 内设计中造成麻烦, 这就需要设计师根据具体的设计布 局选择绿色植物种类, 同时还可以人为的制造适合植物 生长的条件。总之, 在室内陈设设计中充分运用和体现生 态理念, 让人类能够更好的亲近大自然, 缩短与大自然之 间的距离。

\section{4 室内光线色彩设计}

室内采光按照光照方式的不同分为自然采光和人 工照明两种采光方式。一般来说,为让室内或者足够好的 照明效果,在室内环境设计中会采用两者相互搭配、相互 结合的方式。两种采光方式中自然采光的优点为节能降 耗、光线柔和, 能够随着光照的改变进而改变室内的光 线,给人一种安静祥和的氛围。为了能够获得更多的自然 采光, 就需要在进行设计时最大的可能根据太阳光线的 变化来对室内空间进行合理的安排和设计。虽然自然采 光有很多的优点,但是也不能忽略人工照明的重要性, 当 室内的自然光线不能满足人们的需要时, 人工照明作为 唯一的采光方式同样是室内照明中重要的组成部分。人 工照明设计在体现生态理念的同时主要是通过对灯具 的形状、色彩以及布局进行合理的布置, 以此来最大程度 的满足居住者的要求。

\section{5 结语}

由于城市化的加重, 人们把自然生态化设计逐渐融 人到了室内设计中。另外,绿色植物有美化环境、净化空 气、清除有害物质的作用。尤其是随着人们生活质量的 提高, 对电器的使用越发频繁, 使室内的空气质量降低, 这 也促使了人们对绿色植物的向往。绿色植物也成为了大 家在家庭装饰中最喜欢用的方式，也加强了人们对于美 丽的环境和身心健康的理解和认识。在提倡创建和谐社 会的今天, 将观赏植物应用于室内设计也得到了了大家 的重视,观赏性绿色植物的应用是一种需要,一种时尚,同 时也为未来室内装饰设计的发展提供了更多的方向。

\section{[参考文献]}

[1]刘宗娟.建筑施工企业内部控制建设及完善研究 [J].时代金融,2018(35):114+118.

[2]孙建萍.基于内部控制的建筑企业财务管理研究 [J]. 山西农经,2018(23):84+86.

[3]吴晶晶.建筑施工企业内部控制存在的问题与对 策[J].当代会计,2018(12): $55+56$. 